University of Nebraska - Lincoln

DigitalCommons@University of Nebraska - Lincoln

USDA National Wildlife Research Center - Staff Publications
U.S. Department of Agriculture: Animal and Plant Health Inspection Service

2020

\title{
Competing reproductive and physiological investments in an all-female lizard, the Colorado checkered whiptail
}

Lise M. Aubry

Colorado State University - Fort Collins, Lise.Aubry@colostate.edu

Spencer B. Hudson

Utah State University, spencerbrucehudson@gmail.com

Bryan M. Kluever

NWRC, Gainesville, bryan.kluever@usda.gov

Alison C. Webb

Utah State University

Susannah S. French

Utah State University, sfrench@biology.usu.edu

Follow this and additional works at: https://digitalcommons.unl.edu/icwdm_usdanwrc

Part of the Natural Resources and Conservation Commons, Natural Resources Management and

Policy Commons, Other Environmental Sciences Commons, Other Veterinary Medicine Commons,

Population Biology Commons, Terrestrial and Aquatic Ecology Commons, Veterinary Infectious Diseases

Commons, Veterinary Microbiology and Immunobiology Commons, Veterinary Preventive Medicine,

Epidemiology, and Public Health Commons, and the Zoology Commons

Aubry, Lise M.; Hudson, Spencer B.; Kluever, Bryan M.; Webb, Alison C.; and French, Susannah S., "Competing reproductive and physiological investments in an all-female lizard, the Colorado checkered whiptail" (2020). USDA National Wildlife Research Center - Staff Publications. 2375.

https://digitalcommons.unl.edu/icwdm_usdanwrc/2375

This Article is brought to you for free and open access by the U.S. Department of Agriculture: Animal and Plant Health Inspection Service at DigitalCommons@University of Nebraska - Lincoln. It has been accepted for inclusion in USDA National Wildlife Research Center - Staff Publications by an authorized administrator of DigitalCommons@University of Nebraska - Lincoln. 


\title{
Competing reproductive and physiological investments in an all-female lizard, the Colorado checkered whiptail
}

\author{
Lise M. Aubry ${ }^{1,2}$ (D) . Spencer B. Hudson ${ }^{3,4}$ - Bryan M. Kluever ${ }^{5}$ Alison C. Webb ${ }^{3,4}$. \\ Susannah S. French ${ }^{3,4}$
}

Received: 22 July 2020 / Accepted: 19 September 2020 / Published online: 26 September 2020 (c) Springer Nature Switzerland AG 2020

U.S. government works are not subject to copyright.

\begin{abstract}
Organisms in the wild have to allocate limited resources towards competing functions such as reproduction, growth, and self-maintenance. These competing investments create significant changes in physiological activity, and we still know little about the relationship between physiological activity and reproductive investment in natura. We investigated trade-offs between physiological activity and reproductive investment in the parthenogenetic Colorado checkered whiptail, Aspidoscelis neotesselata, across three different sites at the US Army Fort Carson Military Installation near Colorado Springs, CO, throughout the reproductive season in 2018 and 2019. We measured clutch size and reproductive activity and quantified plasma corticosterone (CORT), reactive oxygen metabolites (ROMs), and bacterial killing ability (BKA) to examine how energy-mobilizing hormones, oxidative stress, and immunity change in light of reproductive investment across different sub-populations. Circulating CORT increased with reproductive investment across all sub-populations, and increased clutch size led to a decrease in BKA in one sub-population, suggesting that habitat and nutritional availability may mediate this relationship. Oxidative stress, CORT, and innate immunity were not correlated with the exception of a trade-off between ROMs and BKA. This indicates individuals that have a better capacity to fight-off pathogens suffered increased reactive oxygen metabolites across all sub-populations, independently of habitat characteristics, which has important implications for A. neotesselata conservation.
\end{abstract}

Keywords Corticosterone $\cdot$ Hormone $\cdot$ Immunity $\cdot$ Oxidative stress $\cdot$ Reptile $\cdot$ Reproduction · Trade-off · Whiptail

Lise M. Aubry

lise.aubry@colostate.edu

1 Department of Fish, Wildlife, and Conservation Biology, Colorado State University, Fort Collins, CO 80523-1474, USA

2 Graduate Degree Program in Ecology, Colorado State University, 2545 Research Blvd, Fort Collins, CO 80526, USA

3 Department of Biology, Utah State University, Logan, UT 84322-5305, USA

4 Ecology Center, Utah State University, Logan, UT 84322-5205, USA

5 United States Department of Agriculture, Wildlife Services, National Wildlife Research Center, Florida Field Station, Gainesville, FL 32641-6033, USA 


\section{Introduction}

All organisms have to allocate limited resources among fitness components that are traded against one another (Stearns 1992). These trade-offs are central to life history evolution (Williams 1966) and exist among a variety of physiological functions that are linked to reproduction, self-maintenance, and growth (Zera and Harshman 2001; Monaghan et al 2009). Reproduction in particular is an extremely costly activity that has been hypothesized to come at a cost to self-maintenance via multiple pathways such as an increase in energy-mobilizing hormones, and a decline in immune function (Sheldon and Verhulst 1996; Lochmiller and Deerenberg 2000; French et al 2007; Downs et al 2014; Schultner et al 2014; Adamo 2017).

Trade-offs between reproduction and immune function have been extensively studied (see review by Zera and Harshman 2001). A stronger immune response does not necessarily lead to an improvement in fitness in the wild (French 2017). Evidence often suggests that mounting an immune response is energetically costly and can affect reproductive effort and performance, in line with the idea of a physiological trade-off (Martin et al 2008). Being efficient at allocating energetic and material resources (e.g. proteins) among physiological systems while responding to environmental stressors seems to drive life history decisions (French 2017). Yet, the specific trade-offs driving these decisions remain unpredictable in the wild, and can vary with reproductive stage.

Energy-mobilizing hormones of the glucocorticoids family, including corticosterone (CORT), are key mediators of physiological trade-offs (French et al 2007). CORT can influence physiological systems via multiple pathways that are often dependent on the environmental context (e.g. Wingfield and Romero 2000; Romero and Romero 2002; Romero et al. 2008) but also depend on an individual's energetic state (Moore and Jessop 2003; Angelier and Wingfield 2013; Neuman-Lee and French 2014). Specifically, a prolonged increase in CORT typically exerts negative impacts on organisms (Wingfield 2005), including immunosuppression (Dhabhar 2009), and a decrease in reproductive output (Moore et al 2005). The modulation of CORT secretion that drives the allostatic mediation of reproduction can vary by species and reproductive strategy (see review by Romero and Romero 2002).

Competition between reproductive investment and immune function when internal energetic resources are limiting have been proposed as proximate causes of reproductive costs (Harshman and Zera 2007). Yet, even in the best studied cases (i.e. birds), contradictory responses are often observed likely due to the diversity of measures of immune function used, inconsistency in experimental conditions, or variability across individuals that cannot always be quantified (Speakman 2008). No general consensus has been reached on the direction and intensity of trade-offs that involve reproduction and immunity in natura as animals are exposed to pathogens in a changing environment.

Oxidative status is also hypothesized to be compromised by reproductive investment (Yang et al 2013; Costantini et al 2016). Oxidative stress, or the imbalance arising when the rate of production of reactive oxygen species exceeds the capacity of the antioxidant defense and repair mechanisms (Metcalfe and Alonso-Alvarez 2010), could further mediate such physiological trade-offs. In birds, an increase in reproductive effort is often linked to a decrease in activity of antioxidants or resistance to oxidative stress (e.g. Salmon et al 2001; Alonso-Alvarez et al. 2004; Wiersma et al 2004). In mammals, oxidative damage increases during lactation in some domesticated and laboratory animals (Upreti et al. 2002; Castillo et al 2005; Stier et al 2012), and as litter size increased in the wild (e.g. in chipmunks Tamias striatus Bergeron 2011; in red squirrels Tamiasciurus hudsonicus Fletcher 
et al 2013). In reptiles, increased physiological stress linked to reproductive effort can lead to the overproduction of reactive oxygen metabolites (Webb et al 2019), which may have direct deleterious effects on survival.

Exploring the energetic, hormonal and immune correlates of varying reproductive effort is of particular interest in wild organisms that experience anthropogenic disturbances. We study these trade-offs in a parthenogenetic lizard, the Colorado Checkered Whiptail, Aspidoscelis neotesselata. There are several advantages to studying reproductive tradeoffs in this species: (1) egg cell development proceeds without fertilization by males, and offspring are genetically identical to their mother, potentially limiting additional amounts of individual variability in reproductive effort and investment; (2) the energy required for gamete production (Olsson et al 1997) is likely more equivalent among individuals than in a sexual system, which could remove additional male-female variability; (3) reproductive behaviors such as courtship (Sullivan and Kwiatkowski 2007) and parental care (Case 1978), which demand large energetic costs; (4) finally, one can easily and non-invasively use ultrasonography to quantify variability in one key aspect of reproductive investment, follicular and egg development (Krawchuk and Brooks 1998; Gilman and Wolf 2007).

Clutch size in this "all-female" system varies between 0 and 3 eggs and is likely tied to how each female invests into competing functions such as immunity and reproduction. The Colorado Checkered Whiptail is also a "species of special concern" in Colorado, a status that does not afford any legal protection for the lizards or their habitats despite their exposure to significant levels of anthropogenic disturbance. The species has also been petitioned for listing under the Federal Endangered Species Act (US Fish and Wildlife Service 2015).

In this study, we examined how an energy-mobilizing hormone (i.e. Corticosterone, 'CORT'), immunity (i.e. bacterial killing ability, 'BKA') and oxidative stress (i.e. reactive oxygen metabolites, 'ROMs') were regulated in light of reproductive investments in three sub-populations of $A$. neotesselata. We specifically tested whether reproductive activity and clutch size meditated steroid hormone expression, innate immunity, and (or) oxidative stress. When investigating trade-offs, we further controlled for extrinsic factors that could explain baseline variability in reproductive activity and clutch size, such as seasonality body condition and age-class differences in reproductive investment. Finally, we compared our findings across three sub-populations located in different sections of the US Army Fort Carson (FC) Military Installation near Colorado Springs, CO, that varied in density and habitat characteristics (Aubry et al 2019), but were similar in their level of exposure to anthropogenic military disturbances (i.e. mostly light land navigation and occasional sound disturbance from aerial fly-overs). If habitat conditions permit increased reproductive investment (i.e. clutch size), increased CORT mediation may become necessary. As such, the release and action of CORT on downstream physiology is liable to depend on environmental conditions at each site.

\section{Methods}

\section{Study species}

The Colorado Checkered Whiptail (A. neotesselata, previously Cnemidophorus neotesselata) is a triploid parthenogenetic species (Walker et al. 1997) that only ranges across southeastern Colorado and was recently redefined to include Teller and El Paso counties (Taylor et al 2015a), Las Animas (Taylor et al 2006a), Pueblo (Taylor et al 2006b), 
Fremont (Taylor et al 2015b), and Otero (Walker et al 2012; Taylor et al 2015b, 2016) counties in CO. It can also be found $1600 \mathrm{~km}$ northwest of its natural range in Grant County, WA; a result of an anthropogenically-driven introduction (Weaver et al 2011). The species resulted from hybridization between diploid normally parthenogenetic A. tesselata, and gonochoristic A. sexlineatus. A. neotesselata has since diversified into four distinctive allopatric variants referenced as pattern classes A, B, C, and D (Walker et al. 1997, 2012) within a unisexual mode of reproduction. There is a variant of the species at Fort Carson that is described as pattern class A (Walker et al. 1997; Taylor et al 2015a). The species has had multiple conservation listings, most likely because of its small natural range. It is designated as near threatened by the International Union for Conservation of Nature (IUCN 2007), as a species of special concern by Colorado Parks and Wildlife, and a species at risk by the US Army Work conducted at Fort Carson, where they are locally abundant depending on the level of military disturbance to which animals are subjected (Aubry et al 2019).

\section{Study areas}

Fort Carson US Army installation (FC) is located in unincorporated El Paso County near the city of Colorado Springs, CO. The 55,000-ha installation extends southward into Pueblo and Fremont counties. We sampled and surveyed A. neotesselata at the northern edge of its range within FC. Site selection required working around the constraints of scheduled military training activities.

Of the 37 training areas (TA; numbered 20-56; Fig. 1) that provided suitable habitat for A. neotesselata within FC, we were interested in surveying the TAs that had been recently surveyed by local biologists and had indicated A. neotesselata activity (i.e. observations in 2014: TAs 28, 29, 31, 43; observations between 2007 and 2013: TAs 45, 48, 50, 55 and $56)$. We were provided access to five of those TAs $(29,45,48,50$, and 55). The number of lizards observed was insufficient to support meaningful demographic and physiological sampling at TA 29 and 50. As a result, intensive sampling was focused on TA 45, TA 48, and TA 55; sampling areas within each TA covered 0.99 ha, 6.12 ha, and 4.85 ha, respectively. These sites were similarly exposed to low levels of military training activities (i.e. on-foot navigation and orientation).

We observed A. neotesselata within habitat with Piñon Pine (Pinus edulis), Ponderosa Pine (Pinus ponderosa), and mixed oak trees (Quercus sp.), as well as the cactus Tree Cholla (Cylindropuntia imbricata), and the grass Blue Grama (Bouteloua gracilis), which dominated grasslands in TA 45. The majority of A. neotesselata we observed in the TA 48 study site were concentrated within the dry creek bed and banks consisting of sparsely vegetated shrubland, particularly Shadscale (Atriplex confertifolia), Four-wing Saltbush (Atriplex canescens), James' Seaheath (Frankenia jamesii), and Rubber Rabbitbrush (Chrysothamnus nauseosus). The secondary vegetation type was One-seed Juniper (Juniperus monosperma) and mixed grassland located around the periphery of the sample area TA 55 was similar in habitat structure to TA 48.

\section{Field capture measurements and samples}

\section{Captures and sampling}

The field season ranged from late April-July 2018 and May-July 2019, and expanded on our 2016 pilot physiology study where we sampled and marked 86 individuals over three 


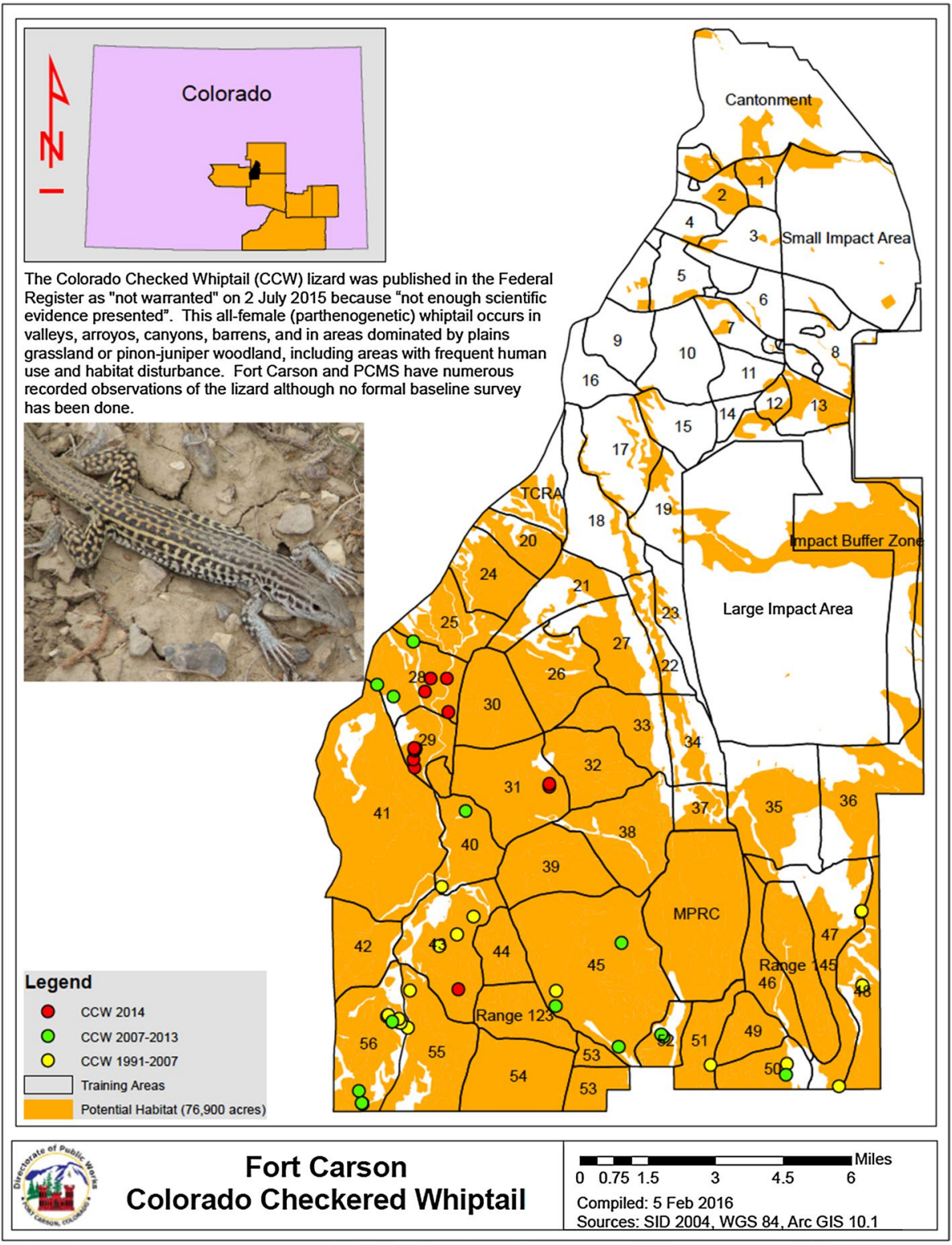

Fig. 1 Aspidoscelis neotesselata surveys conducted in 1991-2007 (yellow dots), 2007-2013 (green dots), and 2014 (red dots) at Fort Carson, CO. Intensive sampling as part of this study was focused on TA 45, TA 48 , and TA 55

locations at FC (91 observations five of which were recaptures) over a 3-month period. A. neotesselata was most active between 08:00 and 11:00 and field crews were typically deployed between 07:00 and 12:00 to conduct field surveys and capture the animals.

Lizards were collected via snaring, a safe and effective technique for capturing this species (Hudson et al 2020). Each captured lizard was sampled for blood within 5 min of 
pursuit time (i.e. 5 min from the beginning of an animal capture attempt). Blood samples ( $\sim 40 \mu \mathrm{L}$, although exact amounts varied based on individual animal size and condition) were immediately collected from the retro-orbital sinus using heparinized capillary tubes (MacLean and Lee 1973) to measure baseline levels of physiological activity (Romero and Reed 2005; Sheriff et al 2011). Blood samples were stored on ice and separation of plasma from red blood cells was performed on site with a portable centrifuge. Samples were stored at $-22{ }^{\circ} \mathrm{C}$ within the same trapping day until assayed later in the summer. Sampling occurred within a standardized timeframe (7:00-12:00) to avoid circadian differences in stimulus-evoked CORT release (MacLean and Lee 1973; Dallman et al 1987; Jones and Gillham 1988; Romero and Wingfield 2001). This sampling period was found to yield no relationship between circulating CORT and time of day (Hudson et al 2020).

Each captured lizard was permanently marked by toe-clipping, which has been found to be harmless to A. neotesselata in the field (Hudson et al 2020; see also Langkilde and Shine 2006). We recorded the date, time of day, body mass, and snout-vent length (SVL) for each captured animal. Using both manual palpation of the abdomen and high-resolution ultrasound (Sonosite Turbo ultrasound unit with an external linear probe (C2020 Fujifilm Sonosite Inc), we assessed the firmness, shape, and number of follicles/eggs to determine reproductive state and clutch size $(0,1,2$, or 3$)$. Once all the data were collected, lizards were released at their respective points of capture.

\section{Ethics statement}

All handling and procedures were approved by the Colorado State University Institutional Animal Care and Use Committee, Protocol ID: 18-7772A "Demographic and Physiological Monitoring of the Colorado Checkered Whiptail on Fort Carson: An Integrated Conservation Approach".

\section{Blood plasma analysis}

For each collected sample, we measured: (1) CORT, a glucocorticoid regulator of physiological trade-offs; (2) BKA, to assess innate immune status via ability to fight-off pathogens; and (3) ROMs, to assess the accumulation of free radicals which can be influenced by metabolic activities such as reproduction. We completed BKA first due to sensitivity of the proteins in this assay, followed by ROMs, and then CORT. Some animals did not have sufficient plasma for all assays and so later assays could not be completed for those individuals. Coefficients of variation (CVs) were calculated using standards that were included in each assay such that comparisons could be made across assays (i.e. inter-assay).

\section{Corticosterone}

Enzyme-linked immunosorbent assay (ELISA) kits were validated and used with blood plasma $(10 \mu \mathrm{L})$ to determine CORT concentrations. The assay was completed in duplicate according to manufacturer guidelines (Enzo Life Sciences, Farmingdale, NY) over 7 plates in total. The CORT ELISAs is based on competitive binding between sheep polyclonal antibodies and plasma hormone that occurs on a donkey anti-sheep immunoglobulin microtiter plate. CORT assay sensitivity included a minimum level of detection at $27 \mathrm{pg} /$ $\mathrm{mL}$ with a mean intra-assay coefficient of variation $(\mathrm{CV})$ of $1.46 \%$ and an inter-assay $\mathrm{CV}$ of $12.19 \%$. 


\section{Bacterial killing assay}

To assess innate immune function for this species, BKA was quantified with a validated volume of blood plasma $(11 \mu \mathrm{L})$. Using the protocol outlined in French and NeumanLee (2012), a 1:2 plasma dilution was combined with $\mathrm{CO}_{2}$-independent media (plus $4 \mathrm{nM}$ L-glutamine), $10^{4}$ colony producing units of Escherichia coli (EPowerTM Microorganisms \#483-581-1, ATCC 8739, MicroBioLogics, St. Cloud, MN, USA), and agar broth on a 96-well microplate. Included were both positive (media and bacteria with no plasma) and negative (media and no plasma or bacteria) controls to account for potential growth and ensure there was no contamination. The plate was incubated for $12 \mathrm{~h}$ and absorbance per well was measured with a microplate reader at $300 \mathrm{~nm}$ (xMark; BioRad Benchmark, Hercules, CA, USA). Bactericidal ability was then calculated as 1 - (absorbance of sample/absorbance of positive controls) $\times 100$. We ran 7 microplates in total with a mean intra-assay $\mathrm{CV}$ of $2.82 \%$ and an inter-assay $\mathrm{CV}$ of $7.88 \%$.

\section{Reactive oxygen metabolites}

Oxidative status was measured using reactive oxygen metabolites (ROMs). Circulating ROMs were quantified using a d-ROMs test kit (MC435, Diacron International, Italy) which detects levels of hydroperoxides that oxidize an alkyl-substituted aromatic amine $\left(\mathrm{A}-\mathrm{NH}_{2}\right)$. Plasma was diluted in an acidic buffered solution $(5 \mu \mathrm{L}: 100 \mu \mathrm{L})$ following "endpoint" mode manufacturer instructions that were adapted for a 96-well microplate (French et al. 2017), and incubated for $90 \mathrm{~min}$ at $37{ }^{\circ} \mathrm{C}$. Values were calculated as absorbance change relative to the standard. The mean intra-assay $\mathrm{CV}$ over 8 plates was $3.26 \%$ and the inter-assay CV was $3.33 \%$.

\section{Statistical analyses}

All analyses and visual representation of data were performed using default packages in RStudio (version 1.2.5001, R Core Team 2019) and additional packages: 'dplyr' (Wickham 2020) and 'ggplot2' (Wickham 2016). The statistical analysis called for One-way ANOVA models when considering single effects, or Two-way ANOVA when considering interactions between independent variables (Mangiafico 2015). We systematically tested for normality of model residuals (using Shapiro's test; Royston 1982) and homogeneity of variance (using Levene's test; Hines and Hines 2000) in our models. To that end, CORT was log-transformed to un-skew its distribution and normalize residuals.

Yet, model assumptions were never met, and we applied non-parametric alternatives instead: the Kruskal-Wallis test, or one-way ANOVA on ranks, and the Mann-Whitney $\mathrm{U}$ test when comparing two groups to untransformed data (Hollander and Douglas 1973). We regrouped variables of interest into new categories (e.g. juveniles or adults with low or high body condition; i.e. 4 groups) and tested for differences in CORT, BKA, and ROMs among groups using the Kruskal-Wallis test. We used the Pairwise Wilcoxon Rank Sum Tests to calculate pairwise comparisons between groups. We used untransformed values for non-parametric analyses, but log-transformed values in figures involving CORT as the dependent variable to minimize its spread for visual purposes (Fig. 3a, b). 
Finally, we explored the potential for trade-offs between immunity and physiological correlates, independently of reproductive investment, using linear regression. We report on intercept and slope parameters, their precision and significance. We adopted a significance level alpha of 0.05 for statistical significance for all analyses.

\section{Results}

Clutch size was observed for 718 individual clutches (Table 1). A subset of 265, 319, and 274 individual samples were collected for CORT, DROMs, and BKA assays, respectively. Sample sizes reported by TA $(45,48,55)$ and month of capture (May, June, and July) over field seasons 2018 and 2019 are presented in Table 1.

\section{Extrinsic drivers of change in reproductive investment}

Clutch size was on average more in TA 45 when compared to other TAs (Kruskal-Wallis, $\chi^{2}=10.864, d f=2, p$ value $=0.004$; Fig. 2a). Adults produced larger clutches than juveniles (Mann-Whitney U, $W=17,048, d f=1, p$ value $<0.001$; Fig. 2b), and clutch size peaked in June and July, with lower vitellogenic investments in May (Kruskal-Wallis $\chi^{2}=192.640, d f=2, p$ value $<0.001$; Fig. $2 \mathrm{c}$ ). Clutch size did not differ across body condition categories (i.e. below vs. above average; Mann-Whitney U, $W=9875.5, d f=1$, $p$ value $=0.149$ ). The same patterns held true for reproductive investment (no eggs versus

Table 1 Number of individuals for which information on clutch size was collected, ranging from no clutch $(0)$, to a clutch size of either 1,2 , or 3 eggs

\begin{tabular}{llll}
\hline & \multicolumn{2}{l}{ Number of clutches of a specific size } \\
\cline { 2 - 4 } & May & June & July \\
\hline TA 45 & & & \\
0 & 0 & $4(19 \%)$ & 0 \\
1 egg & 0 & $5(23.8 \%)$ & 0 \\
2 eggs & 0 & $11(52.4 \%)$ & 0 \\
3 eggs & 0 & $1(0.05 \%)$ & 0 \\
$T A 48$ & & & \\
0 & $126(76.4 \%)$ & $46(16.2 \%)$ & $34(47.9 \%)$ \\
1 egg & $25(15.1 \%)$ & $106(37.5 \%)$ & $26(36.6 \%)$ \\
2 eggs & $14(8.5 \%)$ & $123(43.5 \%)$ & $9(12.7 \%)$ \\
3 eggs & 0 & $8(2.8 \%)$ & $2(2.8 \%)$ \\
$T A 55$ & & & $7(43.7 \%)$ \\
0 & $31(60.8 \%)$ & $16(14.4 \%)$ & $4(25 \%)$ \\
1 egg & $13(25.5 \%)$ & $38(34.2 \%)$ & $4(25 \%)$ \\
2 eggs & $7(13.7 \%)$ & $55(49.5 \%)$ & $1(6.3 \%)$ \\
3 eggs & 0 & $2(1.8 \%)$ & \\
\hline
\end{tabular}

Each individual was only sampled once for clutch size, thus these numbers represent individual observations of Colorado Checkered Whiptails (Aspidoscelis neotesselata) reported by TA $(45,48,55)$ and by month (May, June, and July) at Fort Carson, El Paso County, Colorado. These observations were summed over field seasons 2018 and 2019 
Fig. 2 a Clutch size by training area (i.e. 45,48 , and 55) with significant differences represented by $p$ value $\mathrm{s}$ for each paired comparison. Note that although the distributions (i.e. the median and inter-quartile range, represented by the thick line and edges of the box, respectively) are the same for TA 48 and 55, their mean clutch sizes are significantly different (i.e. TA $48=0.93$ vs. TA $55=1.1 ; p$ value $=0.019$ ). Whiskers represent $95 \%$ confidence intervals; thick horizontal lines show medians, while large black dots represent means; $N S$ non-significant; $* * * * p$ value $<0.0001$; $* * * p$ value $<0.001 ; * * p$ value $<0.01 ; * p$ value $<0.05$. $\mathbf{b}$ Age class comparison of clutch size across all sub-populations where 'A' stands for adults and ' $\mathrm{J}$ ' stands for juveniles. The median and inter-quartile range are represented by the thick line and edges of the box, respectively. Whiskers represent 95\% confidence intervals; thick horizontal lines show medians, while large black dots represent means; $N S$ non-significant; $* * * * p$ value $<0.0001 ; * * * p$ value $<0.001 ; * * p$ value $<0.01$; ${ }^{*} p$ value $<0.05$. c Monthly comparison (i.e. May, June, and July sampling periods) of clutch size across all sub-populations with significant differences represented by $p$ value $\mathrm{s}$ for each paired comparison. The median and inter-quartile range are represented by the thick line and edges of the box, respectively. Whiskers represent $95 \%$ confidence intervals; thick horizontal lines show medians, while large black dots represent means; NS non-significant; $* * * * p$ value $<0.0001 ; * * * p$ value $<0.001 ; * * p$ value $<0.01$; ${ }^{*} p$ value $<0.05$
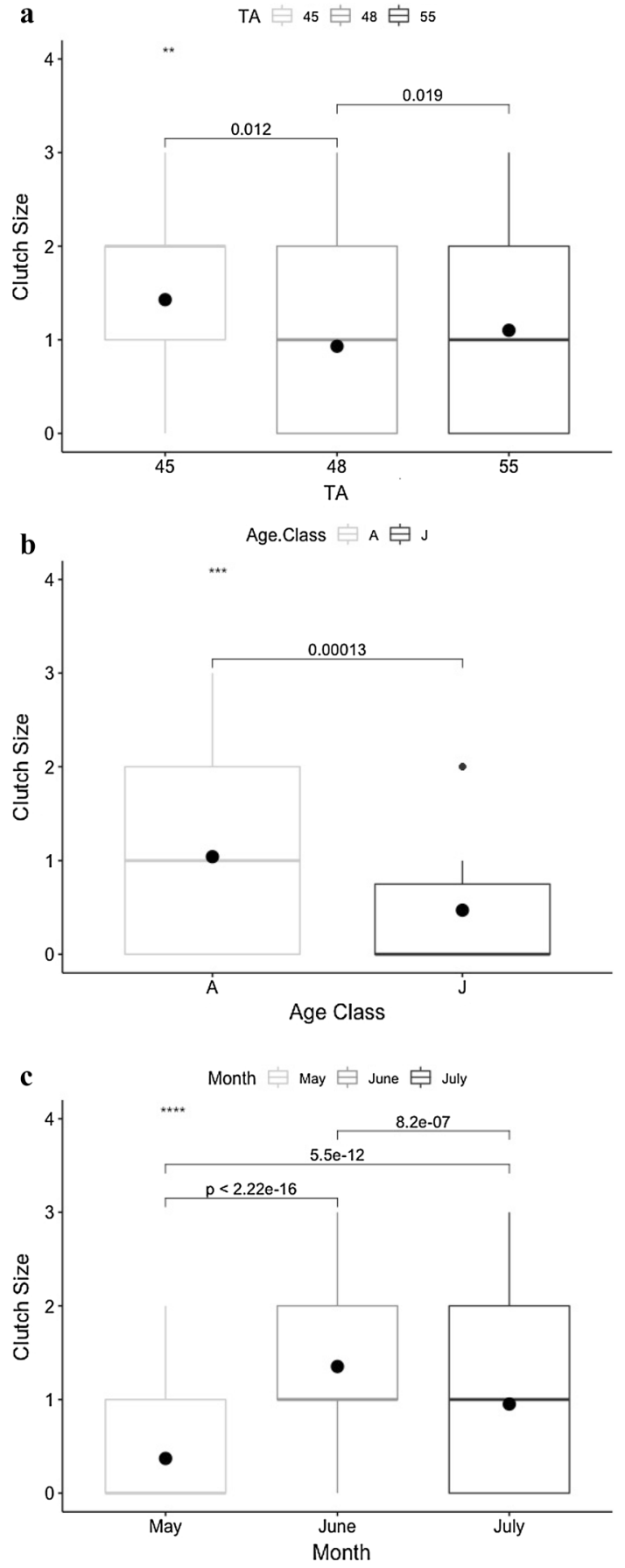
eggs produced) which peaked in June and July, and did not differ across body condition categories; results are not presented here for conciseness.

\section{Corticosterone and reproductive investment}

CORT was significantly different across clutch size, ranging from 0 to 3 eggs (Kruskal-Wallis $\chi^{2}=49.539, d f=3, p$ value $<0.001$; Fig. 3a), and across levels of reproductive investment, when comparing animals that had invested into reproduction (1-3 eggs) versus those that did not (Mann-Whitney $\mathrm{U}, W=2170.5, d f=1, p$ value $<0.001$; Fig. 3b). The effect of clutch size on CORT was significantly different across TAs (Kruskal-Wallis $\chi^{2}=47.82$, $d f=11, p$ value $<0.0001$ ), age classes (Kruskal-Wallis $\chi^{2}=58.468, d f=5, p$ value $<0.0001$ ), month of capture (Kruskal-Wallis $\chi^{2}=71.585, d f=9, p$ value $<0.0001$ ), and body condition (Kruskal-Wallis $\chi^{2}=53.62, d f=7, p$ value $<0.0001$ ). For reproductive investment, this relationship differed across TAs (Kruskal-Wallis $\chi^{2}=63.446, d f=7, p$ value $<0.0001$ ), age classes (Kruskal-Wallis $\chi^{2}=56.159, d f=3, p$ value $<0.0001$ ), month of capture (Kruskal-Wallis $\chi^{2}=69.537, d f=5, p$ value $<0.0001$ ), and body condition. Specifically, CORT was more elevated in adult female among reproductive females (post-hoc pairwise rank sum test comparisons between adults and juveniles $p$ value $=0.0285$ ), and in females of

Fig. 3 a Relationship between clutch size and the energy-mobilizing hormone (i.e. $\log (\mathrm{CORT})$ in $\mathrm{ng} / \mathrm{mL}$ ) across all sub-populations. Significant differences are represented by $p$ value $\mathrm{s}$ for each paired comparison. The median and inter-quartile range are represented by the thick line and edges of the box, respectively. Whiskers represent 95\% confidence intervals; thick horizontal lines show medians, while large black dots represent means; NS non-significant; $* * * * p$ value $<0.0001 ; * * * p$ value $<0.001 ; * * p$ value $<0.01$; ${ }^{*} p$ value $<0.05$. b Relationship between reproductive investment (i.e. absent vs. present) and the energy-mobilizing hormone (i.e. $\log ($ CORT $)$ in $\mathrm{ng} / \mathrm{mL})$ across all sub-populations. Significant differences are represented by $p$ value $\mathrm{s}$ for each paired comparison. The median and inter-quartile range are represented by the thick line and edges of the box, respectively. Whiskers represent 95\% confidence intervals; thick horizontal lines show medians, while large black dots represent means; $N S$ non-significant; $* * * * p$ value $<0.0001 ; * * * p$ value $<0.001 ; * * p$ value $<0.01$; $* p$ value $<0.05$
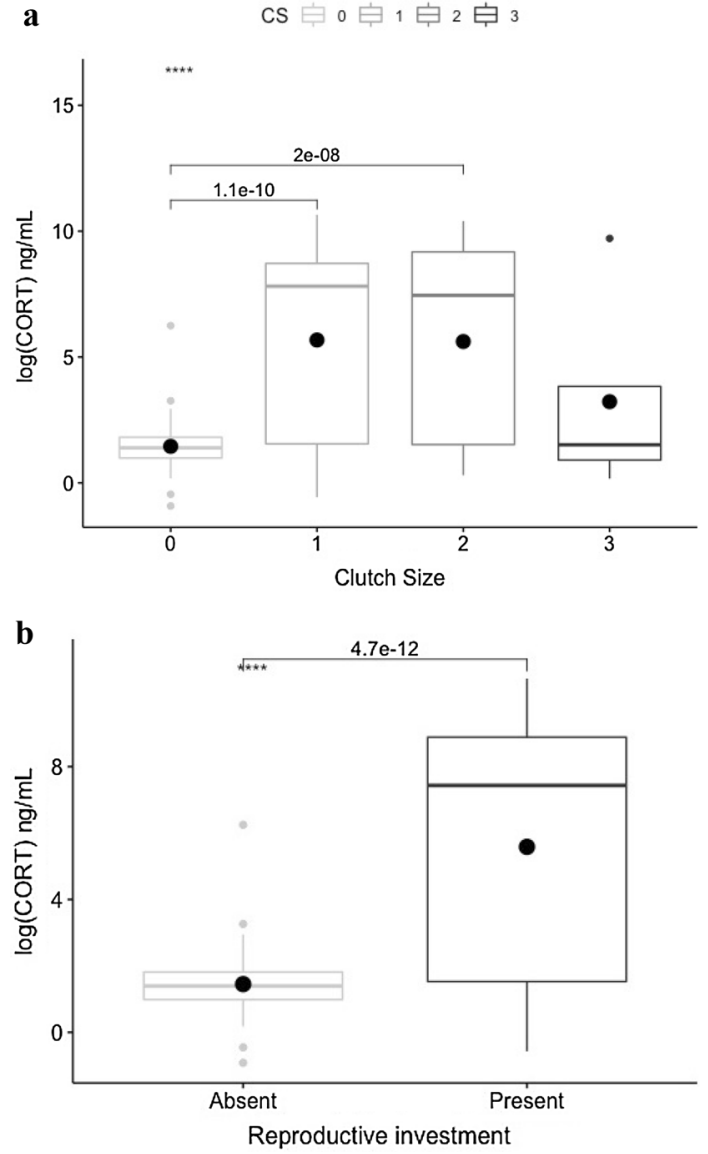
above-average body condition among individuals that did not invest into reproduction (posthoc pairwise rank sum test comparisons $p$ value $=0.002$ ).

\section{Bacterial killing ability and reproductive investment}

BKA was not significantly different across clutch sizes (Kruskal-Wallis $\chi^{2}=0.938$, $d f=3, p$ value $=0.816$ ). However, the relationship between clutch size and BKA was significantly different across TAs (Kruskal-Wallis $\chi^{2}=20.935, d f=11, p$ value =0.034). The relationship between clutch size and BKA did not change with respect to age classes (Kruskal-Wallis $\chi^{2}=4.851, d f=6, p$ value $=0.563$ ), month of capture (Kruskal-Wallis $\chi^{2}=10.602, d f=10, p$ value $=0.389$ ), or body condition (Kruskal-Wallis $\chi^{2}=4.228, d f=7$, $p$ value $=0.753$ ). Although the effect of reproductive investment on BKA was not significant (Mann-Whitney $\mathrm{W}=5719.5, d f=1, p$ value $=0.841$ ), it did significantly change with respect to TA (Kruskal-Wallis $\chi^{2}=15.087, d f=5, p$ value $=0.001$ ), with highest levels reached in TA55, followed by TA48, and TA45. The effect of reproductive investment on BKA, however, did not change with respect to age class (Kruskal-Wallis $\chi^{2}=3.6268, d f=3, p$ value $=0.305$ ), month of capture (Kruskal-Wallis $\chi^{2}=9.045, d f=5, p$ value $=0.107$ ), or body condition (Kruskal-Wallis $\chi^{2}=0.510, d f=3, p$ value $=0.917$ ).

\section{Reactive oxygen metabolites and reproductive investment}

ROMs were not significantly different across clutch sizes (Kruskal-Wallis $\chi^{2}=0.622, d f=3$, $p$ value $=0.891)$. The relationship between clutch size and ROMs did not change across TAs (Kruskal-Wallis $\chi^{2}=15.929, d f=11, p$ value $=0.144$ ), age classes (Kruskal-Wallis $=\chi^{2}=1.208, d f=6, p$ value $=0.976$ ), or body condition (Kruskal-Wallis $\chi^{2}=3.014$, $\mathrm{df}=7, p$ value $=0.884$ ), but did change with respect to month of capture (Kruskal-Wallis $\chi^{2}=36.171, \mathrm{df}=10, p$ value $\left.<0.0001\right)$. Similarly, we did not detect changes in ROMs with respect to reproductive investment (Mann-Whitney $\mathrm{W}=8183, d f=1, p$ value $=0.590$ ). Although this relationship did not change with age class (Kruskal-Wallis $=\chi^{2}=0.898, d f=3$, $p$ value $=0.8258$ ), body condition (Kruskal-Wallis $\chi^{2}=1.789, d f=3, p$ value $=0.617$ ), or TA (Kruskal-Wallis $\chi^{2}=11.798, d f=5, p$ value $=0.058$ ), it did change across months of capture (Kruskal-Wallis $\chi^{2}=31.863, d f=5, p$ value $<0.0001$ ), and was highest in May, followed by June, then July, independently of reproductive investment.

\section{Hormonal, oxidative, and immune correlates}

We further observe that energetic, stress, and immunity metrics were not correlated with the exception of a trade-off between ROMs and BKA. The slope of the linear relationship between ROMS and BKA was indeed positive and significantly different from 0 (Table 2: slope $=0.746$, standard error $=0.213, p$ value $<0.001 ;$ Fig. 4 ), which indicates that individuals that have a better capacity to fight-off pathogens experienced increased ROMs. 
Table 2 Results from linear regressions testing for a relationship between (a) BKA (\%) and ROMs $\left(\mathrm{mg} \mathrm{H}_{2} \mathrm{O}_{2} / \mathrm{dL}\right)$, (b) BKA (\%) and CORT (pg/ $\mathrm{mL}$ ), and (c) CORT and ROMs. Intercept and slope regression parameters are presented below, along with standard errors, t-value, $p$ value, degrees of freedom, and R-squared estimates
Fig. 4 Linear relationship between innate immunity (i.e. \% BKA) and oxidative stress (i.e. dROMs in $\mathrm{mg} \mathrm{H}_{2} \mathrm{O}_{2} / \mathrm{dL}$ ) across all sub-populations with associated R-squared value (27\%) and slope significance. The shaded area represents the $95 \%$ confidence intervals associated with the fitted regression line

\begin{tabular}{lccrl}
\hline & Estimate & SE & t-value & $p$ value \\
\hline (a) BKA versus & ROMs & & & \\
(Intercept) & 41.996 & 2.876 & 14.604 & $<0.001^{* * *}$ \\
ROMs & 0.8102 & 0.1979 & 4.093 & $<0.001^{* * *}$ \\
(b) BKA versus & CORT & & & \\
(Intercept) & 52.729 & 2.246 & 23.477 & $<0.001^{* * *}$ \\
CORT & -0.0003 & 0.0003 & -0.921 & 0.358 \\
(c) CORT versus & ROMs & & & \\
(Intercept) & 3835.32 & 700.27 & 5.477 & $<0.001 * * *$ \\
ROMs & -58.57 & 48.09 & -1.218 & 0.225 \\
\hline
\end{tabular}

Significance codes for $p$ value $\mathrm{s}$ : $* * * p$ value $<0.001$; $* * p$ value $<0.01$; $* p$ value $<0.05$.

(a) Residual standard error: 28.51 on 236 degrees of freedom. Adjusted R-squared: 0.066

(b) Residual standard error: 28.62 on 205 degrees of freedom. Adjusted R-squared: 0.004

(c) Residual standard error: 6521 on 199 degrees of freedom. Adjusted R-squared: 0.002



\section{Discussion}

Our findings highlight differences among sub-populations of A. neotesselata in how an energy-mobilizing hormone and immunity are regulated in light of reproductive investment, but only in one of the three locations sampled. Steroid hormones correlated with reproductive activity and generally increased with reproductive investment and clutch size. In addition, reproductive investment came at a cost to innate immunity under specific circumstances (i.e. location, month of capture, and age-class), and individuals that had a better capacity to fight-off pathogens experienced increased ROMs. 
Circulating CORT was greater among A. neotesselata that invested into reproduction (Fig. 3b). This pattern of CORT release is consistent with females of other lizard species (e.g. Wilson and Wingfield 1992; Woodley and Moore 2002) supporting the notion that reproductive investment is a predictable, yet energetically-demanding challenge (Wingfield 2005; Moore et al 2005). The extent of reproductive investment (i.e. clutch size) in $A$. neotesselata was further reflective of the associated energetic costs, as increased clutch size often corresponded with greater CORT levels (Fig. 3a). The exception to this relationship was when clutches included three follicles/eggs, which was a rare occurrence in our data.

Seasonal progression in vitellogenic stage, clutch number, or seasonality could further obscure this finding (Mitchell et al. 2018), since most observation of clutch size equal, or greater than one, happened with greater frequency in June and July, when compared to May (Table 1). Trade-offs between clutch size and follicle/egg size could also explain this finding since females that produced larger clutches likely produce smaller follicles to offset the energetic cost of a large clutch.

Differences in energy usage and availability may also relate to intrinsic characteristics such as age, ability to secure resources, and body condition (e.g. Bleu et al 2013). CORT was slightly more elevated in females of above-average body condition among individuals that did reproduction, but this difference was not significant (Post-hoc pairwise rank sum test comparisons $p$ value $=0.998$ ). Because this result did not change across locations, environmental conditions may not help explain this finding either. Behavioral differences could be a driving factor, but determining this would call for a more fine-scaled study of individual behaviors, resource acquisition, and allocation (e.g. Bleu et al 2013).

Hudson et al. (2020) studied the same species, but different sub-populations of $A$. neotesselata at FC in 2016, and compared similar physiological metrics (CORT, BKA) in response to reproductive phenology ranging from May to August. They observed patterns of CORT release that differed between breeding (May-June) and non-breeding seasons (August) such that CORT secretion was either suppressed for reproductively active lizards, or greater for inactive lizards recovering from reproductive investment. This pattern of CORT secretion suggests that seasonality and reproductive phenology are important in explaining the relationship between CORT release and reproductive investment in this species. Our results are derived only from a "within-reproductive season" comparison (May-July) which suggest that CORT is only released during more critical periods of reproductive investment during the active season, hence the differences in CORT between no clutch and clutch sizes with at least one follicle or egg. Hudson and colleagues' results further suggest that once the active season ends (August) even more circulating CORT is released to mobilize what energy stores remain, with variations in CORT values (May-July) collectively below what was observed in Hudson and colleagues (2020) study in August.

Glucocorticoids are released to support metabolically demanding activities such as reproduction (Wingfield and Romero 2000; Romero and Romero 2002; Sapolsky et al. 2000; Romero and Butler 2007). Downs et al (2018) discussed how an acute increase in CORT may facilitate reproduction, and stimulate or redistribute immunological defenses (Adamo 2017; Sapolsky et al. 2000; Romero and Butler 2007; Martin 2009). Yet, sustained elevated concentrations of glucocorticoids from chronic stress can suppress immunity and prevent reproduction (Singer et al. 1996). Reproductive investment was associated with compromised innate immunity in A. neotesselata, considering increased clutch size correlated with a decrease in BKA, albeit only for the sub-population at TA 45 (Fig. 5). Many species reduce immune defenses when investing into reproduction (Bonneaud et al 2003; French et al 2007), however, population differences in reproductive-immune trade-offs are 


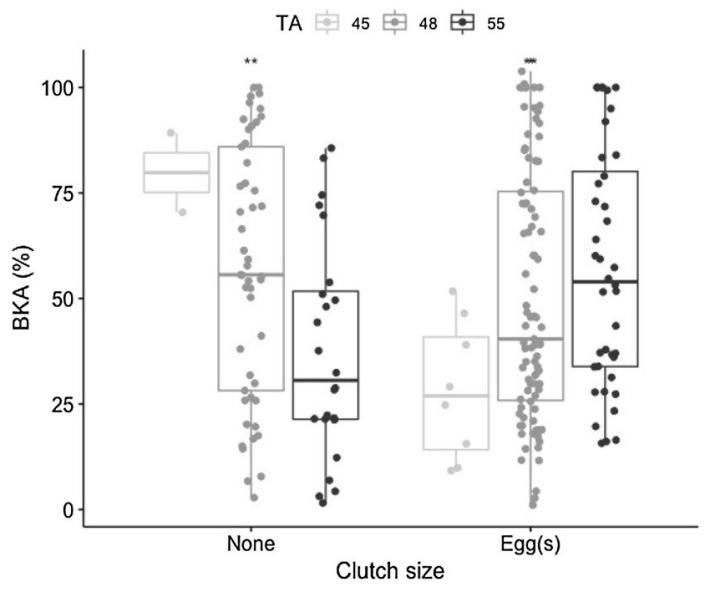

Fig. 5 Relationship between reproductive investment and innate immunity (i.e. BKA in \%) for each subpopulation (i.e. TA 45, 48, and 55). Whiskers represent $95 \%$ confidence intervals; thick horizontal lines show medians, while large black dots represent means; NS non-significant; $* * * * p$ value $<0.0001$; *** $p$ value $<0.001$; $* *$ value $<0.01 ; * p$ value $<0.05$. A post-hoc pairwise rank sum test indicated that there were significant differences in BKA across TAs for individuals that did not produce a clutch (TA48 vs. TA55, $p$ value $=0.008$ ) and for those that invested into reproduction (TA45 vs. TA48, $p$ value $=0.046$; TA45 vs. TA55, $p$ value $=0.008$ ), as well as within TAs (TA45 reproductive investment vs. none, $p$ value $=0.044$; TA55 reproductive investment vs. none, $p$ value $=0.009$ ), and across TAs and levels of reproductive investment (non-reproductive females in TA48 vs. reproductive females in TA45, $p$ value $=0.010$ )

rarely documented (but see Lucas and French 2012). Although our results support the idea that this trade-off can change across populations depending on the environmental context experienced, only few observations were collected at TA45, and all observations were collected at peak reproduction in June, which could be driving this result.

Though clutch sizes were also larger for this sub-population (TA 45) compared to others (Fig. 5), this particular location may be amenable to elevated reproductive investment and associated immune costs. Indeed, the availability of nutritional resources that help regulate energetic state has been shown to mediate trade-offs between immunity and reproductive output through integrative physiological pathways (French et al 2007; Downs et al 2014; Adamo 2017). Interestingly, habitat composition at TA 45 (Fig. 1) is quite different from other sampled locations with Piñon and Ponderosa Pine, mixed oak trees, Tree Cholla, and Blue Grama dominating the landscape. We suspect both nutrition and habitat characteristics, which are intrinsically linked, may explain why reproductive output is particularly elevated at this location. However, TA 45 was only visited in June, which seems to be when peak reproductive activity occurs (Fig. 2c). A disproportionate amount of reproductive investment may therefore be represented for this particular site when compared to others (Fig. 2a). Nonetheless, relatively greater CORT levels for the sub-population at TA 45 may be indirectly related to their concurrent immunosuppression (Singer et al. 1996). Investigations examining the arthropod communities in the various TAs, paired with studies aimed at determining if foraging efficiency (e.g. capture rate, handling time) differs by TAs, could help shed light on our findings.

Finally, ROMs directly corresponded with BKA for A. neotesselata, providing evidence for potential ROMs associated with immune defense (Yang et al 2013). Indeed, reactive oxygen species play many important roles in the immune system, and are intimately involved in various aspects of the immune response such as host defense, immune cell activation, and immune 
suppression (Yang et al 2013). The positive association among BKA and ROMs suggests that these females may be utilizing elevated free radicals to fight pathogens. Alternatively, animals investing in elevated immunological defenses may suffer an oxidative cost (Costantini and Møller 2009). This alternative scenario is also likely because immune responses are known to be energetically costly and could result in oxidative stress.

\section{Conservation implications}

Coarse-scale distribution models developed by the Fort Carson Conservation Branch indictae that that Colorado checkered whiptail available habitat encompasses nearly half of Fort Carson lands available to training (Parks and Kluever 2017). Hence the proper monitoring and management of COCW on Fort Carson will be essential in maintain existing populations in the near future.

That TAs differed in clutch size could be important information for the conservation of A. neotesselata at Fort Carson. If in the near future, there becomes a greater need to sustain or enhance subpopulations of $A$. neotesselata, managers could focus conservation efforts in areas where clutch sizes have been shown to be highest (e.g. TA 48). But we recommend the influence of clutch size on population state variables (e.g. density) be explored before assuming these areas are more productive for the species (Aubry et al 2019).

An additional consideration is that although all studied sub-populations are thought to be exposed to similar levels of military activity, differences in such activities (e.g. number of land navigation events and aircraft fly-overs) during the reproductive season have never between directly quantified and contrasted across locations. This will be the focus of a future study on aerial noise pollution and ground disturbance on A. neotesselausa physiology at FC. In addition, predation risk may vary across TAs which could in turn impact immune and (or) oxidative stress in A. neotesselata; that the areas varied in vegetation communities/composition adds plausibility to this notion. Future data collection will help quantify differences in levels of anthropogenic disturbances that may help explain our current findings.

Acknowledgements We would like to warmly thank Anna-Joy Lehmicke and the Fort Carson Directorate of Public Works, Conservation Branch, for logistical assistance in facilitating our research, as well as Roger Peyton for administrative support. We would like to thank Doug Eifler, Maria Eifler, and all of the volunteers and technicians who helped collect this data, especially Hannah Caracalas, Carina Kusaka, Rachael Pedersen, and Catherine Staley, and students from the Colorado State University and the University of Kansas ESA SEEDS Chapters. Financial support was provided through US Fish and Wildlife Cooperative Agreement F17AC00326. This research was also supported in part by the US Department of Agriculture, Animal and Plant Health Inspection Service, Wildlife Services, National Wildlife Research Center. The findings and conclusions in this publication have not been formally disseminated by the US Department of Agriculture and should not be construed to represent any agency determination or policy. Field methods were approved through Colorado State University IACUC 18-7772A.

\section{Compliance with ethical standards}

Conflict of interest The authors declare no conflicts of interest.

\section{References}

Adamo SA (2017) The stress response and immune system share borrow and reconfigure their physiological network elements: evidence from the insects. Horm Behav 88:25-30 
Alonso-Alvarez C, Bertrand S, Devevey G, Prost J, Faivre B, Sorci G (2004) Increased susceptibility to oxidative stress as a proximate cost of reproduction. Ecol Lett 7(5):363-368

Angelier F, Wingfield JC (2013) Importance of the glucocorticoid stress response in a changing world: theory hypotheses and perspectives. Gen Comp Endocrinol 190:118-128

Aubry LM, Eifler D, Utsumi K, French SS (2019) Demographic assessment of the triploid parthenogenetic lizard Aspidoscelis neotesselatus at the northern edge of its range. Herpetol Conserv Biol 14(2):411

Bergeron P (2011) Les déterminants de l'aptitude phénotypique chez le tamia rayé (Tamias striatus). Université de Sherbrooke, Sherbrooke

Bleu J, Le Galliard JF, Fitze PS, Meylan S, Clobert J, Massot M (2013) Reproductive allocation strategies: a long-term study on proximate factors and temporal adjustments in a viviparous lizard. Oecologia 171(1):141-151

Bonneaud C, Mazuc J, Gonzalez G, Haussy C, Chastel O, Faivre B et al (2003) Assessing the cost of mounting an immune response. Am Nat 161:367-379

Case TJ (1978) Endothermy and parental care in the terrestrial vertebrates. Am Nat 112(987):861-874

Castillo C, Hernandez J, Bravo A, Lopez-Alonso M, Pereira V, Benedito JL (2005) Oxidative status during late pregnancy and early lactation in dairy cows. Vet J 169(2):286-292

Costantini D, Møller AP (2009) Does immune response cause oxidative stress in birds? A meta-analysis. Comp Biochem Physiol Part A Mol Integrat Physiol 153(3):339-344

Costantini D, Casasole G, AbdElgawad H, Asard H, Eens M (2016) Experimental evidence that oxidative stress influences reproductive decisions. Funct Ecol 30(7):1169-1174

Dallman MF, Akana SF, Cascio CS, Darlington DN, Jacobson L, Levin N (1987) Regulation of ACTH secretion: variations on a theme of B. In: Proceedings of the 1986 Laurentian hormone conference. Academic Press, pp 113-173

Dhabhar FS (2009) Enhancing versus suppressive effects of stress on immune function: implications for immunoprotection and immunopathology. NeuroImmunoModulation 16(5):300-317

Downs CJ, Adelman JS, Demas GE (2014) Mechanisms and methods in ecoimmunology: integrating within-organism and between-organism processes. Integr Comp Biol 54:340-352

Downs CJ, Boan BV, Lohuis TD, Stewart KM (2018) Investigating relationships between reproduction immune defenses and cortisol in Dall sheep. Front Immunol 9:105

Fletcher QE, Selman C, Boutin S, McAdam AG, Woods SB, Seo AY et al (2013) Oxidative damage increases with reproductive energy expenditure and is reduced by food-supplementation. Evolution 67(5):1527-1536

French SS (2017) Trade-offs in ecoimmunology: costs for individuals and populations. Integrat Comp Biol 57:265-265

French SS, Neuman-Lee LA (2012) Improved ex vivo method for microbiocidal activity across vertebrate species. Biology Open 1(5):482-487

French SS, DeNardo DF, Moore MC (2007) Trade-offs between the reproductive and immune systems: facultative responses to resources or obligate responses to reproduction? Am Nat 170:79-89

French SS, Neuman-Lee LA, Terletzky PA, Kiriazis NM, Taylor EN, DeNardo DF (2017) Too much of a good thing? Human disturbance linked to ecotourism has a "dose-dependent" impact on innate immunity and oxidative stress in marine iguanas, Amblyrhynchus cristatus. Biol Conserv 210:37-47

Gilman CA, Wolf BO (2007) Use of portable ultrasonography as a nondestructive method for estimating reproductive effort in lizards. J Exp Biol 210(11):1859-1867

Harshman LG, Zera AJ (2007) The cost of reproduction: the devil in the details. Trends Ecol Evol 22(2):80-86

Hines WGS, Hines RJO (2000) Increased power with modified forms of the Levene (med) test for heterogeneity of variance. Biometrics 56:451-454

Hudson SB, Kluever BM, Webb AC, French SS (2020) Steroid hormones energetic state and immunocompetence vary across reproductive contexts in a parthenogenetic lizard. Gen Comp Endocrinol 288:113372

International Union for Conservation of Nature (2007) IUCN red list of threatened species. www.iucnredlis t.org

Jones MT, Gillham B (1988) Factors involved in the regulation of adrenocorticotropic hormone/beta-lipotropic hormone. Physiol Rev 68(3):743-818

Krawchuk MA, Brooks RJ (1998) Basking behavior as a measure of reproductive cost and energy allocation in the painted turtle, Chrysemys picta. Herpetologica, 112-121

Langkilde T, Shine R (2006) How much stress do researchers inflict on their study animals? A case study using a scincid lizard Eulamprus heatwolei. J Exp Biol 209:1035-1043

Lochmiller RL, Deerenberg C (2000) Trade-offs in evolutionary immunology: just what is the cost of immunity? Oikos 88:87-98 
Lucas LD, French SS (2012) Stress-induced tradeoffs in a free-living lizard across a variable landscape: consequences for individuals and populations. PLoS ONE 7(11):e49895

MacLean GS, Lee AK (1973) Wilson KJ (1973) A simple method of obtaining blood from lizards. Copeia 2:338-339

Mangiafico SS (2015) An R companion for the handbook of biological statistics version 1.3.2

Martin LB, Weil ZM, Nelson RJ (2008) Seasonal changes in vertebrate immune activity: mediation by physiological trade-offs. Philos Trans R Soc B Biol Sci 363(1490):321-339

Martin LB (2009) Stress and immunity in wild vertebrates: timing is everything. Gen Comp Endocrinol 163:70-76

Metcalfe NB, Alonso-Alvarez C (2010) Oxidative stress as a life-history constraint: the role of reactive oxygen species in shaping phenotypes from conception to death. Funct Ecol 24(5):984-996

Mitchell TS, Hall JM, Warner DA (2018) Female investment in offspring size and number shifts seasonally in a lizard with single-egg clutches. Evolut Ecol 32(2-3):231-245

Monaghan P, Metcalfe NB, Torres R (2009) Oxidative stress as a mediator of life history trade-offs: mechanisms measurements and interpretation. Ecol Lett 12(1):75-92

Moore IT, Jessop TS (2003) Stress reproduction and adrenocortical modulation in amphibians and reptiles. Horm Behav 43(1):39-47

Moore IT, Bonier F, Wingfield JC (2005) Reproductive asynchrony and population divergence between two tropical bird populations. Behav Ecol 16(4):755-762

Neuman-Lee LA, French SS (2014) Wound healing reduces stress-induced immune changes: evidence for immune prioritization in the side-blotched lizard. J Comp Physiol B 184(5):623-629

Olsson M, Madsen T, Shine R (1997) Is sperm really so cheap? Costs of reproduction in male adders Vipera berus. Proc R Soc Lond B 264(1380):455-459

Parks E, Kluever B (2017) Colorado checkered whiptail pilot study on Fort Carson, Colorado. Report prepared for: directorate of Public Works Environmental Division, Fort Carson

R Core Team (2019) R: a language and environment for statistical computing. R Foundation for Statistical Computing, Austria

Romero LM, Wingfield JC (2001) Regulation of the hypothalamic-pituitary-adrenal axis in free-living pigeons. J Comp Physiol B 171(3):231-235

Romero LM, Romero RC (2002) Corticosterone responses in wild birds: the importance of rapid initial sampling. Condor 104:129-135

Romero LM, Reed JM (2005) Collecting baseline corticosterone samples in the field: is under $3 \mathrm{~min}$ good enough? Comp Biochem Physiol A Mol Integr Physiol 140(1):73-79

Romero ML, Butler LK (2007) Endocrinology of stress. Int J Comp Psychol 20(2)

Romero LM, Meister CJ, Cyr NE, Kenagy GJ, Wingfield JC (2008) Seasonal glucocorticoid responses to capture in wild free-living mammals. Am J Physiol Regul Integr Comp Physiol 294:R614-R622

Royston P (1982) An extension of Shapiro and Wilk's W test for normality to large samples. Appl Stat $31: 115-124$

Salmon AB, Marx DB, Harshman LG (2001) A cost of reproduction in Drosophila melanogaster: stress susceptibility. Evolution 55(8):1600-1608

Sapolsky RM, Romero LM, Munck AU (2000) How do glucocorticoids influence stress responses? Integrating permissive suppressive stimulatory and preparative actions. Endocr Rev 21:55-89

Schultner J, Moe B, Chastel O, Tartu S, Bech C, Kitaysky AS (2014) Corticosterone mediates carryover effects between breeding and migration in the kittiwake Rissa tridactyla. Mar Ecol Prog Ser 496:125-133

Sheldon BC, Verhulst S (1996) Ecological immunology: costly parasite defences and tradeoffs in evolutionary ecology. Trends Ecol Evol 11:317-321

Sheriff M, Dantzer J, Delehanty B, Palme B, Boonstra R (2011) Measuring stress in wildlife: techniques for quantifying glucocorticoids. Oecologia 166(4):869-887

Singer F, Harting A, Symonds K, Coughenour M (1996) Density dependence compensation and environmental effects on elk calf mortality in Yellowstone National Park. J Wildl Manag 61:12-25

Speakman JR (2008) The physiological costs of reproduction in small mammals. Philos Trans R Soc B Biol Sci 363(1490):375-398

Stearns SC (1992) The evolution of life histories. Oxford University Press, New York, p 249

Stier A, Reichert S, Massemin S, Bize P, Criscuolo F (2012) Constraint and cost of oxidative stress on reproduction: correlative evidence in laboratory mice and review of the literature. Front Zool 9(1):37

Sullivan BK, Kwiatkowski MA (2007) Courtship displays in anurans and lizards: theoretical and empirical contributions to our understanding of costs and selection on males due to female choice. Funct Ecol 21(4):666-675 
Taylor HL, Droll BA, Walker JM (2006a) Proximate causes of a phylogenetic constraint on clutch size in parthenogenetic Aspidoscelis neotesselata (Squamata: Teiidae) and range expansion opportunities provided by hybridity. J Herpetol 40:294-304

Taylor HL, Rondeau RJ, Sovell J (2006b) Alternative ontogenetic pathways to color Pattern Class B in a newly discovered population of parthenogenetic Aspidoscelis neotesselata (Squamata: Teiidae). Herpetol Rev 37:40-44

Taylor HL, Livo LJ, Martin DJ, Maynard WR, Estep A, Clawges R, Roth D, Kellner J, Jackson T (2015a) New northern distribution records for pattern classes A B and D of Aspidoscelis neotesselata (Colorado Checkered Whiptail) in Colorado and biogeographic sources of northern colonists. Herpetol Rev 46:312-319

Taylor HL, Walker JM, Cole CJ, Dessauer HC (2015b) Morphological divergence and genetic variation in the triploid parthenogenetic teiid lizard Aspidoscelis neotesselata. J Herpetol 49:491-501

Taylor HL, Wilmes AJ, Garey LK, Montgomery CE, Livo LJ, Walker JM (2016) Rare color-pattern misfits in indigenous arrays of parthenogenetic Aspidoscelis neotesselata (Colorado Checkered Whiptail). Herpetol Rev 47:561-568

Upreti K, Chaki SP, Misro MM (2002) Evaluation of peroxidative stress and enzymatic antioxidant activity in liver and kidney during pregnancy and lactation in rats. Health Popul Perspect Issues 25:177-185

US Fish and Wildlife Service Endangered and threatened wildlife and Plants; 90-Day findings on 31 petitions Published 7/01/2015. US Federal Register Document Number: 2015-16001

Walker JM, Cordes M, Taylor HL (1997) Parthenogenetic Cnemidophorus tesselatus complex (Sauria: Teiidae): a neotype for C. tesselatus (Say 1823) redescription of the taxon and description of a new triploid parthenogenetic species. Herpetologica 53:233-259

Walker JM, Taylor HL, Manning GJ, Cordes JE, Montgomery CE, Livo LJ, Keefer S, Loeffler C (2012) Michelle's lizard: identity relationships and ecological status of an array of parthenogenetic lizards (genus Aspidoscelis: Squamata: Teiidae) in Colorado USA. Herpetol Conserv Biol 7:227-248

Weaver RE, O'Connor AP, Wallace JL, King JM, Walker JM (2011) Discovery of the parthenogenetic Colorado Checkered Whiptail Aspidoscelis neotesselata (Squamata: Teiidae) in Washington state. Northwest Nat 92:233-236

Webb AC, Iverson JB, Knapp CR, DeNardo DF, French SS (2019) Energetic investment associated with vitellogenesis induces an oxidative cost of reproduction. J Anim Ecol 88(3):461-472

Wickham H (2016) Programming with ggplot2. ggplot2. Springer, Cham, pp 241-253

Wickham H, Wickham MH (2020) Package 'plyr'. https://cran.rproject.org/web/packages/dplyr/dplyr.pdf

Wiersma P, Selman C, Speakman JR, Verhulst S (2004) Birds sacrifice oxidative protection for reproduction. Proc R Soc Lond B 271(5):S360-S363

Williams GC (1966) Natural selection the costs of reproduction and a refinement of Lack's principle. Am Nat 100(916):687-690

Wilson BS, Wingfield JC (1992) Correlation between female reproductive condition and plasma corticosterone in the lizard Uta stansburiana. Copeia 92:691-697

Wingfield JC (2005) The concept of allostasis: coping with a capricious environment. J Mammal 86(2):248-254

Wingfield JC, Romero LM (2000) Adrenocortical responses to stress and their modulation in free-living vertebrates. In: McEwen BS (ed) Handbook of physiology. Oxford University Press, New York, pp 211-236

Woodley SK, Moore MC (2002) Plasma corticosterone response to an acute stressor varies according to reproductive condition in female tree lizards (Urosaurus ornatus). Gen Comp Endocrinol 128:143-148

Yang Y, Bazhin AV, Werner J, Karakhanova S (2013) Reactive oxygen species in the immune system. Int Rev Immunol 32(3):249-270

Zera AJ, Harshman LG (2001) The physiology of life history trade-offs in animals. Annu Rev Ecol Syst 32(1):95-126

Publisher's Note Springer Nature remains neutral with regard to jurisdictional claims in published maps and institutional affiliations. 